\title{
Engagement With COVID-19 Public Health Measures in the United States: A Cross-sectional Social Media Analysis from June to November 2020
}

Daisy Massey ${ }^{1}$, BA; Chenxi Huang ${ }^{1}$, PhD; Yuan Lu ${ }^{1,2}, \mathrm{ScD}$; Alina Cohen ${ }^{3}$, MS, MBA; Yahel Oren ${ }^{3}$, MS; Tali Moed ${ }^{3}$, BS; Pini Matzner ${ }^{3}$, PhD; Shiwani Mahajan ${ }^{1,2}$, MBBS, MHS; César Caraballo ${ }^{1,2}$, MD; Navin Kumar ${ }^{4}$, MPhil; Yuchen Xue $^{5}$, MA; Qinglan Ding ${ }^{6}$, PhD, MBBS; Rachel Dreyer ${ }^{7}$, PhD; Brita Roy ${ }^{8,9}$, MD, MPH, MHS; Harlan Krumholz ${ }^{1,2,10}$, $\mathrm{MD}, \mathrm{SM}$

\footnotetext{
${ }^{1}$ Center for Outcomes Research and Evaluation, Yale New Haven Hospital, New Haven, CT, United States

${ }^{2}$ Section of Cardiovascular Medicine, Department of Internal Medicine, Yale School of Medicine, New Haven, CT, United States

${ }^{3}$ Signals Analytics, New York, NY, United States

${ }^{4}$ Department of Sociology, Yale University, New Haven, CT, United States

${ }^{5}$ Foundation for a Smoke-Free World, New York, NY, United States

${ }^{6}$ College of Health and Human Sciences, Purdue University, West Lafayette, IN, United States

${ }^{7}$ Department of Emergency Medicine, Yale School of Medicine, New Haven, CT, United States

${ }^{8}$ Department of Chronic Disease Epidemiology, Yale School of Public Health, New Haven, CT, United States

${ }^{9}$ Department of Medicine, Yale School of Medicine, New Haven, CT, United States

${ }^{10}$ Department of Health Policy and Management, Yale School of Public Health, New Haven, CT, United States
}

\section{Corresponding Author:}

Harlan Krumholz, MD, SM

Section of Cardiovascular Medicine

Department of Internal Medicine

Yale School of Medicine

1 Church St

Suite 200

New Haven, CT

United States

Phone: 12037645885

Email: harlan.krumholz@yale.edu

\section{Abstract}

Background: COVID-19 has continued to spread in the United States and globally. Closely monitoring public engagement and perceptions of COVID-19 and preventive measures using social media data could provide important information for understanding the progress of current interventions and planning future programs.

Objective: The aim of this study is to measure the public's behaviors and perceptions regarding COVID-19 and its effects on daily life during 5 months of the pandemic.

Methods: Natural language processing (NLP) algorithms were used to identify COVID-19-related and unrelated topics in over 300 million online data sources from June 15 to November 15, 2020. Posts in the sample were geotagged by NetBase, a third-party data provider, and sensitivity and positive predictive value were both calculated to validate the classification of posts. Each post may have included discussion of multiple topics. The prevalence of discussion regarding these topics was measured over this time period and compared to daily case rates in the United States.

Results: The final sample size included $9,065,733$ posts, $70 \%$ of which were sourced from the United States. In October and November, discussion including mentions of COVID-19 and related health behaviors did not increase as it had from June to September, despite an increase in COVID-19 daily cases in the United States beginning in October. Additionally, discussion was more focused on daily life topics $(n=6,210,255,69 \%)$, compared with COVID-19 in general ( $n=3,390,139,37 \%)$ and COVID-19 public health measures $(\mathrm{n}=1,836,200,20 \%)$. 
Conclusions: There was a decline in COVID-19-related social media discussion sourced mainly from the United States, even as COVID-19 cases in the United States increased to the highest rate since the beginning of the pandemic. Targeted public health messaging may be needed to ensure engagement in public health prevention measures as global vaccination efforts continue.

(J Med Internet Res 2021;23(6):e26655) doi: 10.2196/26655

\section{KEYWORDS}

COVID-19; public perception; social media; infodemiology; infoveillance; infodemic; social media research; social listening; social media analysis; natural language processing; Reddit data; Facebook data; COVID-19 public health measures; public health; surveillance; engagement; United States; cross-sectional; Reddit; Facebook; behavior; perception; NLP

\section{Introduction}

As COVID-19 continues its spread in the United States, a key to controlling the spread while vaccination efforts continue is to enlist the public in risk-mitigation behaviors [1,2]. Studying the public's social media posts regarding COVID-19 public health measures may provide information about targets of interventions, progress toward behavior goals, and the risk of future outbreaks [3-9]. Although real-time reports on pandemic-related tests and mortality are widely available, there are fewer opportunities to gain near real-time insight into behaviors and beliefs about the pandemic.

Social media, which people are using now more than ever to communicate, has served as a useful data source for providing rapid insight into the public's behaviors and beliefs during the pandemic [10-13]. Studies have noted a high prevalence of COVID-19-related discussion-including such topics as hygiene, shortages, and the spread of misinformation - and an increase in COVID-19-related discussion as COVID-19 cases increase $[5,14,15]$. However, existing findings are based on evidence during only the beginning of the outbreak, from December 2019 to April 2020, and the range of topics and keywords explored is also limited [7,14-19]. Additionally, studies analyzing COVID-19 behaviors and beliefs on social media have primarily used Twitter as their source, which has several limitations [14-16,19]. Most notably, highly rated retweets are more likely to come from spam and bot accounts, which are also actively posting about COVID-19, and can obscure the targeting of signals from human discussions [20-22]. Further, previous studies each focused on a particular aspect of the pandemic, such as misinformation relating to the pandemic, without comparing the volume of discussion related to multiple aspects to determine the public's relative focus on particular pandemic-related issues and behaviors. Therefore, there is a need to assess how the public's current reaction to the pandemic has changed since the early stages, by examining broad online discussion from more diverse sources.

Accordingly, we measured the prevalence of online discussion that included topics in the categories of daily life, which may or may not be related to COVID-19, and COVID-19-related public health, from June through November 2020. We also assessed the correlation between prevalence of discussion topics and US COVID-19 new daily case rates (incidence). In measuring these trends in social media data and the COVID-19 incidence rate in the United States, we sought to elucidate the US public's engagement with COVID-19-related public health measures, which are crucial to addressing the current pandemic.

\section{Methods}

\section{Data Sources}

The data sample consisted of unstructured, English-language posts from forums, such as Reddit, Facebook public pages, and 4Chan, and comments from news sites (Table S1 in Multimedia Appendix 1) [23]. We defined forums as thread lists or topic-specific pages, and excluded social media sites including Twitter, YouTube, Instagram, and LinkedIn [24]. Signals Analytics, an advanced analytics consulting firm that conducted the analysis, accessed these data sources through a third-party data vendor, NetBase $[25,26]$. These social media posts were geotagged by NetBase both directly, by using geolocation data from posts, and indirectly, by using author profiles and unique domain codes (such as .uk). All data were deidentified by NetBase before being transferred to Signals Analytics.

In addition to the social data, the study included US COVID-19 case data from the COVID-19 Dashboard by the Center for Systems Science and Engineering at Johns Hopkins University [27]. These data were updated daily using a public application programming interface (API) and included total number of deaths, new daily deaths, total active cases, and daily new cases [28].

No personal identifying information (eg, usernames, emails, or IP addresses) was shared as part of the analysis or reporting process. This study was exempted from Institutional Review Board review by Yale University as it did not engage in research involving human subjects.

\section{Approach}

To determine trends in social media discussion during the COVID-19 pandemic, we collected data posts from all internet sources and applied natural language processing (NLP) algorithms to identify and classify mentions of COVID-19, COVID-19-related public health measures, and daily life topics (Table S2 in Multimedia Appendix 1).

NetBase ran a daily query that we designed based on our project scope on over 300 million online data sources from June 15 to November 15, 2020 (Methods 1 in Multimedia Appendix 1). There were several steps to narrow the sample retrieved from the query to include only posts relevant to our research question (Figure S1 in Multimedia Appendix 1). First, NLP algorithms were run to remove advertisements and pornography-related sites and posts (Methods 2 in Multimedia Appendix 1). Next, a taxonomy of topics was applied (Methods 3 in Multimedia Appendix 1). The posts that did not include discussion of topics 
from the taxonomy were deleted. Finally, all news articles and blog posts were deleted from the sample, so that the only remaining data posts were from social outlets (forums and comments on news sites).

The taxonomy was comprised of two categories, COVID-19-related public health measures and daily life behaviors, each of which included multiple topics (Methods 4 in Multimedia Appendix 1). COVID-19 mentions was also an individual topic in the taxonomy, independent of either category. Any post that directly mentioned COVID-19 by name or synonym, including slang such as "Miss Rona," was classified as including a COVID-19 mention (Table S2 in Multimedia Appendix 1). Taxonomy categories and topics were not exclusive, so that a post was classified as belonging to each taxonomy topic and category that it contained mention of (Table S2 in Multimedia Appendix 1).

Once all posts were classified according to the topics in the taxonomy, we measured trends in these topics over time by tracking the total number of posts that included mentions of each taxonomy topic and category. Classifications of topics and categories were not mutually exclusive, so the same post was able to be classified into multiple topics across any category. Trends were visualized by taxonomy category, COVID-19 mentions, and by the most commonly mentioned taxonomy topics. These trends were visualized with the COVID-19 incidence rate in the United States. We chose to correlate the trends in taxonomy topics with trends in the COVID-19 incidence rate rather than the COVID-19 death rate based on previous literature, which found a correlation between trends in online social chatter and COVID-19 incidence [3,5].

This approach allowed us to identify changes in both topics that prior research in the early stage of the outbreak had shown to be prevalent in COVID-19 discussion, and topics from daily life and COVID-19 literature reviews that were not previously known to be found in COVID-19 discussion, but that may have become apparent as COVID-19 cases or current events changed [15,16,29-33]. Additionally, our approach removed redundant posts, limiting the effect of bots and reposts (Methods 3 in Multimedia Appendix 1). The taxonomy classification was validated by calculating positive predictive value and sensitivity (Methods 5 in Multimedia Appendix 1). We also validated the methodology by applying it to US-specific current events and found that the approach revealed an increase in online social discussion when the given current event topic was most relevant (Figure S2 in Multimedia Appendix 1). This methodology was shown to reveal insights into outbreak characterization and event prediction for the e-cigarette or vaping use-associated lung injury outbreak [34].

\section{Results}

The final data sample consisted of 9,065,733 online social posts that mentioned at least one of the topics in our taxonomy from June 15 to November 15, 2020 (Table 1). The majority (87\%) of posts in our sample came from sources that were categorized as forums, including Reddit, Facebook, and 4Chan (Table 2; Table S1 in Multimedia Appendix 1) [23]. The minority of posts (13\%) in our sample were derived from comment sections on news sites, including The Hill, a media source focused on politics and business, and Breitbart, a right-leaning media source (Table 2; Table S1 in Multimedia Appendix 1) [35,36]. Most posts in the sample were not able to be directly geotagged due to sources' data privacy measures and restrictions. A minority were geotagged as from the United States, with the remaining geotagged as from a country other than the United States (Table S3 in Multimedia Appendix 1). Using indirect geotagging provided by NetBase, it was estimated that about $70 \%$ of all initial posts collected by the search query were from the United States. In an independent data sample of 100 posts classified by manual review, the algorithm had a positive predictive value of over $80 \%$, which was calculated as the number of posts correctly classified by the taxonomy using NLP algorithms divided by the number of all posts classified by the taxonomy. This was a higher accuracy measure than is found in comparable social media research [30]. Sensitivity was calculated as the number of correct classifications of a topic using the NLP algorithms divided by the total number of posts for the topic identified by manual screening, and we found that our taxonomy approach led to an average classification rate of $92 \%$ sensitivity.

Within the data sample, 6,210,255 (69\%) posts were classified as including discussion of daily life topics, while 3,390,139 (37\%) contained mentions of COVID-19, and 1,836,200 (20\%) posts were classified as including discussion of COVID-19-related public health topics (Table 1). The most prevalent topics among the daily life posts were sex life $(\mathrm{n}=887,457,14 \%)$, food $(\mathrm{n}=838,513,14 \%)$, and financial concerns $(n=710,757,11 \%)$. The most prevalent topic in COVID-19-related public health behaviors posts was wearing face masks $(n=1,120,344,61 \%)$, followed by lockdowns $(n=457,705,25 \%)$, and social distancing $(n=242,105,13 \%)$.

Online social posts including COVID-19 mentions and discussion of COVID-19-related public health behaviors increased in June 2020, as COVID-19 cases also increased, but remained stagnant as cases began to increase in October (Figure 1). Discussion about wearing face masks was most prevalent in mid-July, during the summer wave (mid-June to early September) of COVID-19 cases, and remained at pre-June levels in October and November, with the exception of a sharp increase on October 2, 2020 (Figure 2). 
Table 1. Number of posts by taxonomy topic from June 15 to November $15,2020(\mathrm{~N}=9,065,733)^{\mathrm{a}}$.

\begin{tabular}{|c|c|}
\hline Relevant taxonomy categories (percent classified within all posts) and topics & Number of posts with mentions (percent classified within category) \\
\hline COVID-19-related public health topics (20) & $1,836,200$ \\
\hline Wearing face mask & $1,120,344(61)$ \\
\hline Lockdown & $457,705(25)$ \\
\hline Social distancing & $242,105(13)$ \\
\hline Quarantine & $94,301(5)$ \\
\hline Testing & $87,712(5)$ \\
\hline Excessive handwashing & $64,679(4)$ \\
\hline Contact tracing & $31,775(2)$ \\
\hline Reopening & $16,681(1)$ \\
\hline Screening & $14,569(1)$ \\
\hline Wearing gloves & $11,531(1)$ \\
\hline Disinfection & $11,076(1)$ \\
\hline Wearing face shield & $10,104(1)$ \\
\hline Daily life taxonomy topics (69) & $6,210,255$ \\
\hline Sex life & $887,457(14)$ \\
\hline Food & $838,513(14)$ \\
\hline Financial & $710,757(11)$ \\
\hline Travel & $651,426(10)$ \\
\hline Smoking/vaping & $476,468(8)$ \\
\hline Mass gatherings & $451,815(7)$ \\
\hline Virtual communication & $414,549(7)$ \\
\hline Alcohol consumption & $398,229(6)$ \\
\hline Religion & $285,538(5)$ \\
\hline New skills/hobbies acquisition/DIY & $280,155(5)$ \\
\hline Drug use & $257,819(4)$ \\
\hline News/media consumption & $257,415(4)$ \\
\hline Reading & $246,074(4)$ \\
\hline Physical activity & $205,116(3)$ \\
\hline Work from home & $198,057(3)$ \\
\hline Socializing in person & $177,522(3)$ \\
\hline Stockpiling & $171,421(3)$ \\
\hline Relaxation techniques & $164,262(3)$ \\
\hline Excess sleep & $127,623(2)$ \\
\hline Pets & $109,510(2)$ \\
\hline Postponing plans & $98,626(2)$ \\
\hline Childcare & $97,735(2)$ \\
\hline Public transportation & $94,414(2)$ \\
\hline Reduced sleep quality & $88,196(1)$ \\
\hline Home school & $80,153(1)$ \\
\hline Non-COVID-19 hospital visits & $77,278(1)$ \\
\hline Doctor well visit & $72,235(1)$ \\
\hline Funerals & $45,394(1)$ \\
\hline
\end{tabular}




\begin{tabular}{ll}
\hline Relevant taxonomy categories (percent classified within all posts) and topics & Number of posts with mentions (percent classified within category) \\
\hline Family-centered time & $28,106(0)$ \\
Outdoor culture & $21,546(0)$ \\
Births & $17,283(0)$ \\
Telehealth & $11,574(0)$ \\
Smokeless tobacco consumption & $2136(0)$ \\
COVID-19 mentions (37) & $3,390,139$ \\
\hline
\end{tabular}

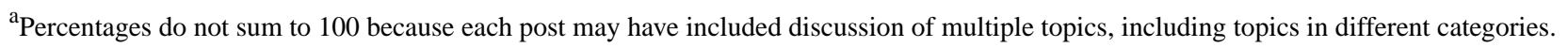

Table 2. Number of posts by source type from June 15 to November 15, 2020.

\begin{tabular}{lllll}
\hline $\begin{array}{l}\text { Category of COVID-19 } \\
\text { discussion topic }\end{array}$ & $\begin{array}{l}\text { Posts with mentions of } \\
\text { COVID-19-related public } \\
\text { health behavior } \\
(\mathrm{N}=1,836,200), \mathrm{n}(\%)\end{array}$ & $\begin{array}{l}\text { Posts with mentions of daily } \\
\text { life }(\mathrm{N}=6,210,255), \mathrm{n}(\%)\end{array}$ & $\begin{array}{l}\text { Posts with mentions of COVID-19 } \\
(\mathrm{N}=3,390,139), \mathrm{n}(\%)\end{array}$ & $\begin{array}{l}\text { Total data sample } \\
(\mathrm{N}=9,065,733), \mathrm{n}(\%)\end{array}$ \\
\hline Forums & $1,494,401(81)$ & $5,714,446(92)$ & $2,749,451(81)$ & $7,928,599(87)$ \\
Comments & $341,799(19)$ & $495,809(8)$ & $640,688(19)$ & $1,137,134(13)$ \\
\hline
\end{tabular}

Figure 1. Online social discussion categories versus US daily new COVID-19 cases (June 15 to November 15, 2020).

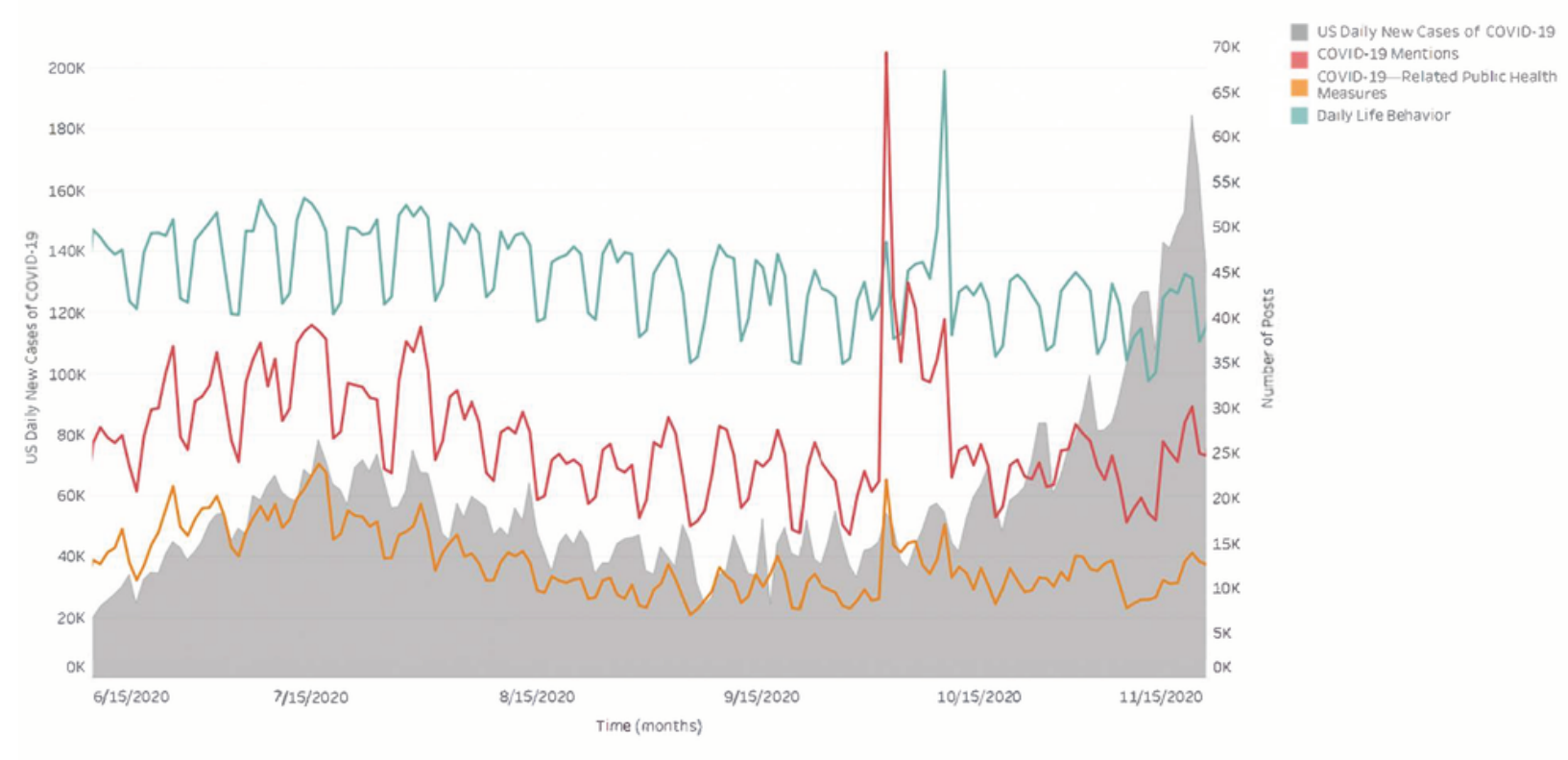


Figure 2. Public health measures online social discussion versus US daily new COVID-19 cases (June 15 to November 15, 2020).

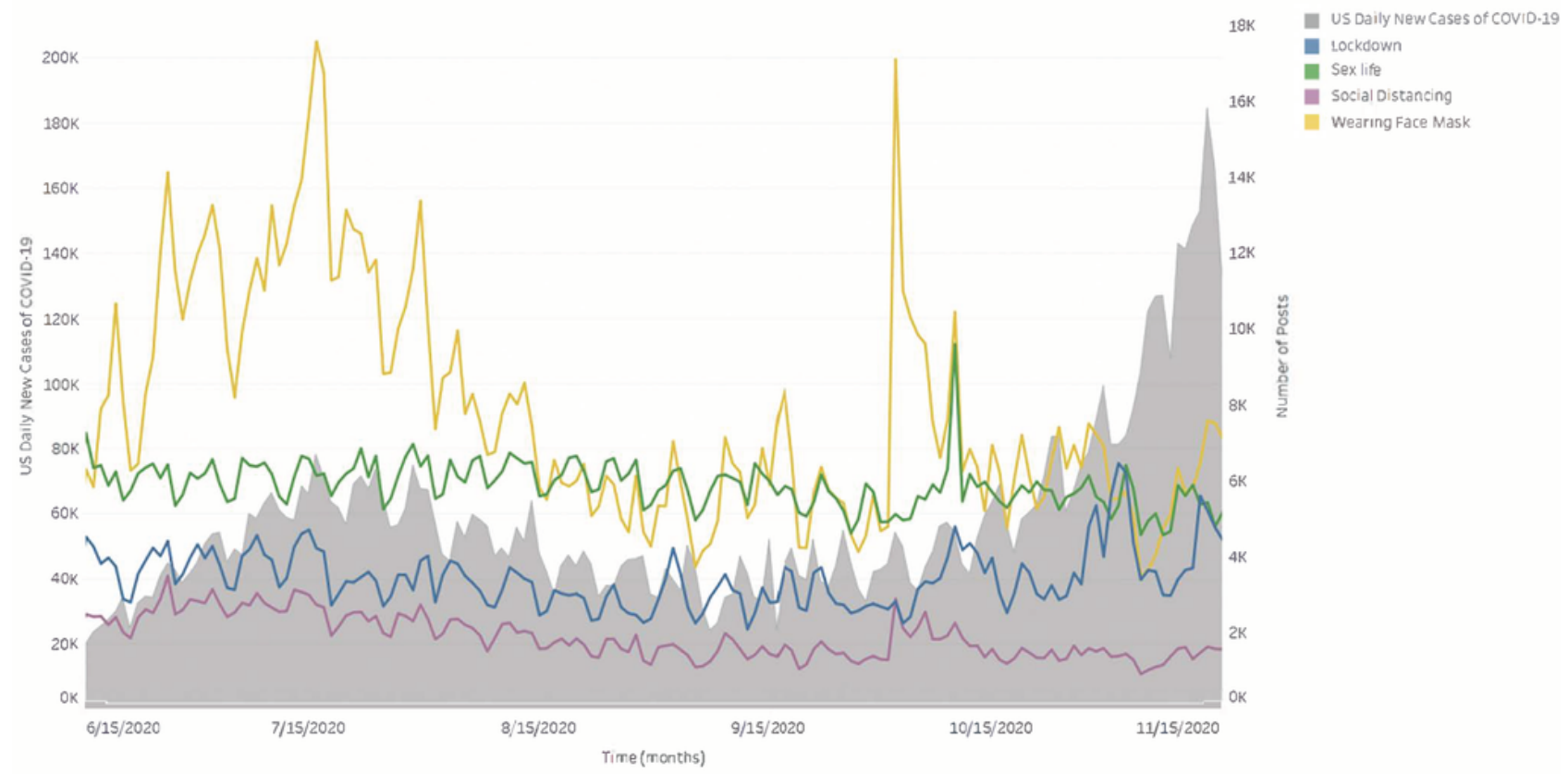

\section{Discussion}

\section{Principal Findings}

Our study had several important findings. From June to November 2020, predominantly US-based online social chatter was more focused on daily life than it was on public health behaviors relating to COVID-19. In addition, although discussion relating to COVID-19 and related public health behaviors appeared to increase with rising US cases in the summer wave (early June to early September), the volume of COVID-19-related discussion was lower in the wave that began in the fall (mid-October), despite the fact that, during the fall wave, COVID-19 cases increased to their highest rates since the pandemic began [37]. In particular, discussion of wearing face masks, the most prevalent of any COVID-19 public health behavior we studied, declined in mid-July despite the pandemic continuing and evidence that wearing face masks has not been universally adopted in the United States, and increased only minimally once cases began to increase again in early October $[38,39]$. One exception to this finding was the brief but stark increase in COVID-19-related discussion on October 2, 2020, which coincided with the announcement that President Donald Trump had contracted COVID-19 [40]. Our finding that daily life topics were more prevalent in social media chatter than COVID-19-related public health behaviors and mentions of COVID-19 is not immediately surprising given the differences in scope. Nevertheless, we applied consistent methods over time, and the decrease of COVID-19-related discussion in the context of the fall rise in COVID-19 cases differs from the pattern we visualized in the summer wave.

Our study expanded upon previous COVID-19-related social media analyses in that our sources used forums and comments on news sites instead of Twitter and our study was conducted in later phases of the pandemic. Our study sources included forums and comments on news sites, which we believe was an advantage for a few reasons. First, forums are unique to other forms of social media in that they tend to include more text, with greater character allowances and less frequent use of hashtags. This allows the NLP algorithms to be more accurately applied, because forum users include more context to which inclusion and exclusion criteria can be applied. Reddit has also been found to include more discussion than links to external sources, again providing more context to analyze [41]. Second, forums, such as Reddit and public Facebook pages, and comments on news sites, are already focused on specific topics and therefore have more in-depth discussions on the same topic, as opposed to other social media sites, which more often share updates from individual users or links to other sites. The added context from in-depth discussions also allows for more accurate NLP classification. Third, as discussed earlier, retweets driven by spam and bot accounts on Twitter can obscure the targeting of signals from human discussion [20-22]. 
Due to these differences in study design and time period, our findings may not be consistent with those of previous studies from the first wave of the COVID-19 pandemic. However, future research may investigate whether the cause of the different findings is a significant difference between the type of social chatter found on forums and that found on Twitter and other social media platforms, or whether the different findings are due to a temporal trend of a decreased focus on COVID-19. Although we found that online social chatter was more focused on daily life than it was on COVID-19 public health behaviors, previous research found the opposite. For instance, one study from March 2020 that used data from Twitter found that social media discussion about COVID-19-related health topics was more common than discussion about daily life topics such as socializing, the economy, or politics [42]. Earlier research also found that COVID-19-related public health measures were discussed not only more often than social topics, but also more often than other COVID-19-related topics [7,15]. Thus, our finding that online social chatter from June to November was more focused on daily life than it was on COVID-19 public health behaviors may indicate that the public's focus on COVID-19 preventative health behaviors had decreased since previous studies were conducted in March and April, or our results may have differed from these earlier studies because our study used different data sources and excluded Twitter. There have been related studies that have analyzed social media data on Reddit - a major source of data in our analysis — during the pandemic; however, none of these studies addressed our research question directly, which was how levels of COVID-19-related public health discussion compared to levels of daily life and COVID-19-related discussion over time. We noted three studies conducted during the time period from January to May 2020 discovered and measured common COVID-19-related topics among online Reddit posts without determining the relative prevalence of COVID-19-related public health discussion to daily life discussion [43-45]. One additional study found that, from February to May 2020, there was a positive correlation between COVID-19-related news coverage and COVID-19-related discussion on the r/Coronavirus subreddit, but that the COVID-19-related discussion declined after sustained media coverage, showing that public attention saturates [46].

Although our results cannot be compared to previous studies to show that public perception changed from the spring wave to the summer and fall waves, there is precedent for the interpretation that the public's focus on COVID-19 public health measures waned during the fall months. As public health experts warned against relaxing preventive behaviors as pandemic fatigue grew, activity and traffic data indicated that people may have stopped adhering to public health recommendations to stay home and avoid close contact with people outside their household [47-50]. The decline of chatter regarding wearing face masks, and the relative low rates of discussions on other COVID-19-related public health behaviors, may reflect that social media engagement with these issues decreased as the pandemic progressed, and remained low among the US population as the pandemic continued to confront a high COVID-19 daily case rate.

Our study has several limitations. First, although our third-party data provider, NetBase, reported that about $70 \%$ of posts were from the United States based on indirect geotagging methods, we do not know the location for most posts according to our direct geotagging methods, which were only able to tag about $20 \%$ of posts (Table S3 in Multimedia Appendix 1). As a result, we cannot make international comparisons, but our data set is more representative of the United States than of any other country. Second, the number of posts included in our data set was much lower than previous studies, likely due to the types of data sources used, which excluded social media sites such as Twitter in order to exclude noise that might have obscured signals in data, and our methodology, which included removing posts not relevant to our more refined taxonomy. We used a stringent exclusion criterion with a list of prespecified keywords that may also have led to a smaller sample size, but our approach aimed to create a sample with high accuracy levels. Third, we were not able to include sentiment analysis or other content analysis in our study, which is an area for further exploration. Finally, there is no demographic information available from the data posts directly due to privacy considerations and data use agreements. Thus, we cannot determine whether our data sample contains biases due to the demographics of the people who posted. For instance, Reddit, which was the most common forum source for our data sample, has been found to be used by a younger, male audience [51,52].

\section{Conclusion}

In this study of predominantly US-based COVID-19 social media data from June to November 2020, we observed that COVID-19 and relevant public health measures were discussed less than daily life behaviors on social media, and that discussion on wearing face masks decreased throughout the summer and into the fall, while cases increased. These discussion rates may reveal a need for increased public health messaging as the pandemic continues.

\section{Acknowledgments}

This work was supported by the project Insights about the COVID Pandemic Using Public Data IRES PD: 20-005872, with funding from the Foundation for a Smoke-Free World.

\section{Authors' Contributions}

AC, TM, PM, and YO from Signals Analytics had full access to the data in the study and take responsibility for the integrity of the data and the accuracy of the data analysis. DM from Yale School of Medicine takes full responsibility for the data interpretation and writing. $\mathrm{CH}$ from Yale School of Medicine contributed to analyzing the data. YL, SM, CC, NK, YX, QD, RD, BR, HK contributed to editing the manuscript. 


\section{Conflicts of Interest}

YL is supported by the National Heart, Lung, and Blood Institute (K12HL138037) and the Yale Center for Implementation Science. RD is supported by an American Heart Association Transformational Project Award (\#19TPA34830013) and a Canadian Institutes of Health Research Project Grant (RN356054-401229). In the past three years, HK received expenses and/or personal fees from UnitedHealth, IBM Watson Health, Element Science, Aetna, Facebook, the Siegfried and Jensen Law Firm, Arnold and Porter Law Firm, Martin/Baughman Law Firm, F-Prime, and the National Center for Cardiovascular Diseases in Beijing. He is an owner of Refactor Health and HugoHealth, and had grants and/or contracts from the Centers for Medicare \& Medicaid Services, Medtronic, the U.S. Food and Drug Administration, Johnson \& Johnson, and the Shenzhen Center for Health Information. The remaining authors have no disclosures to report.

\section{Multimedia Appendix 1}

Supplementary data.

[DOCX File, 172 KB-Multimedia Appendix 1]

\section{References}

1. Anderson RM, Heesterbeek H, Klinkenberg D, Hollingsworth TD. How will country-based mitigation measures influence the course of the COVID-19 epidemic? Lancet 2020 Mar 21;395(10228):931-934 [FREE Full text] [doi: 10.1016/S0140-6736(20)30567-5] [Medline: 32164834]

2. Pan A, Liu L, Wang C, Guo H, Hao X, Wang Q, et al. Association of Public Health Interventions With the Epidemiology of the COVID-19 Outbreak in Wuhan, China. JAMA 2020 May 19;323(19):1915-1923 [FREE Full text] [doi: 10.1001/jama.2020.6130] [Medline: $\underline{32275295]}$

3. Signorini A, Segre AM, Polgreen PM. The use of Twitter to track levels of disease activity and public concern in the U.S. during the influenza A H1N1 pandemic. PLoS One 2011 May 04;6(5):e19467 [FREE Full text] [doi: 10.1371/journal.pone.0019467] [Medline: 21573238]

4. Husnayain A, Shim E, Fuad A, Su ECY. Assessing the community risk perception toward COVID-19 outbreak in South Korea: evidence from Google and NAVER relative search volume. MedRxiv. Preprint published online on April $29,2020$. [doi: $10.1101 / 2020.04 .23 .20077552]$

5. Lin Y, Liu C, Chiu Y. Google searches for the keywords of "wash hands" predict the speed of national spread of COVID-19 outbreak among 21 countries. Brain Behav Immun 2020 Jul;87:30-32 [FREE Full text] [doi: 10.1016/j.bbi.2020.04.020] [Medline: $\underline{\text { 32283286] }}$

6. Puri N, Coomes EA, Haghbayan H, Gunaratne K. Social media and vaccine hesitancy: new updates for the era of COVID-19 and globalized infectious diseases. Hum Vaccin Immunother 2020 Nov 01;16(11):2586-2593. [doi: 10.1080/21645515.2020.1780846] [Medline: 32693678]

7. Wang X, Zou C, Xie Z, Li D. Public Opinions towards COVID-19 in California and New York on Twitter. medRxiv. Preprint published online on July 14, 2020 [FREE Full text] [doi: 10.1101/2020.07.12.20151936] [Medline: $\underline{\text { 32699856] }}$

8. Bavel JJV, Baicker K, Boggio PS, Capraro V, Cichocka A, Cikara M, et al. Using social and behavioural science to support COVID-19 pandemic response. Nat Hum Behav 2020 May;4(5):460-471. [doi: 10.1038/s41562-020-0884-z] [Medline: $\underline{32355299]}$

9. Malecki K, Keating JA, Safdar N. Crisis Communication and Public Perception of COVID-19 Risk in the Era of Social Media. Clin Infect Dis 2021 Feb 16;72(4):697-702 [FREE Full text] [doi: 10.1093/cid/ciaa758] [Medline: 32544242]

10. Koeze E, Popper N. The Virus Changed the Way We Internet. The New York Times. 2020 Apr 07. URL: https://www. nytimes.com/interactive/2020/04/07/technology/coronavirus-internet-use.html [accessed 2021-06-15]

11. Fagherazzi G, Goetzinger C, Rashid MA, Aguayo GA, Huiart L. Digital Health Strategies to Fight COVID-19 Worldwide: Challenges, Recommendations, and a Call for Papers. J Med Internet Res 2020 Jun 16;22(6):e19284 [FREE Full text] [doi: 10.2196/19284] [Medline: 32501804]

12. Li S, Feng B, Liao W, Pan W. Internet Use, Risk Awareness, and Demographic Characteristics Associated With Engagement in Preventive Behaviors and Testing: Cross-Sectional Survey on COVID-19 in the United States. J Med Internet Res 2020 Jun 16;22(6):e19782 [FREE Full text] [doi: 10.2196/19782] [Medline: 32501801]

13. Brady WJ, Crockett MJ, Van Bavel JJ. The MAD Model of Moral Contagion: The Role of Motivation, Attention, and Design in the Spread of Moralized Content Online. Perspect Psychol Sci 2020 Jul;15(4):978-1010. [doi: 10.1177/1745691620917336] [Medline: 32511060 ]

14. Lwin MO, Lu J, Sheldenkar A, Schulz PJ, Shin W, Gupta R, et al. Global Sentiments Surrounding the COVID-19 Pandemic on Twitter: Analysis of Twitter Trends. JMIR Public Health Surveill 2020 May 22;6(2):e19447 [FREE Full text] [doi: 10.2196/19447] [Medline: 32412418]

15. Singh L, Bansal S, Bode L, Budak C, Chi G, Kawintiranon K, et al. A first look at COVID-19 information and misinformation sharing on Twitter. ArXiv. Preprint posted online on March 31, 2020. [Medline: $\underline{32550244]}$ 
16. Abd-Alrazaq A, Alhuwail D, Househ M, Hamdi M, Shah Z. Top Concerns of Tweeters During the COVID-19 Pandemic: Infoveillance Study. J Med Internet Res 2020 Apr 21;22(4):e19016 [FREE Full text] [doi: 10.2196/19016] [Medline: $\underline{32287039]}$

17. Massaad E, Cherfan P. Social Media Data Analytics on Telehealth During the COVID-19 Pandemic. Cureus 2020 Apr 26;12(4):e7838 [FREE Full text] [doi: 10.7759/cureus.7838] [Medline: 32467813]

18. Mackey TK, Li J, Purushothaman V, Nali M, Shah N, Bardier C, et al. Big Data, Natural Language Processing, and Deep Learning to Detect and Characterize Illicit COVID-19 Product Sales: Infoveillance Study on Twitter and Instagram. JMIR Public Health Surveill 2020 Aug 25;6(3):e20794 [FREE Full text] [doi: 10.2196/20794] [Medline: $\underline{32750006}$ ]

19. Mackey T, Purushothaman V, Li J, Shah N, Nali M, Bardier C, et al. Machine Learning to Detect Self-Reporting of Symptoms, Testing Access, and Recovery Associated With COVID-19 on Twitter: Retrospective Big Data Infoveillance Study. JMIR Public Health Surveill 2020 Jun 08;6(2):e19509 [FREE Full text] [doi: 10.2196/19509] [Medline: 32490846]

20. Chu Z, Gianvecchio S, Wang H, Jajodia S. Who is tweeting on Twitter: human, bot, or cyborg? In: Proceedings of the 26th Annual Computer Security Applications Conference.: Association for Computing Machinery; 2010 Presented at: 26th Annual Computer Security Applications Conference; December 6-10, 2010; Austin, TX URL: https://www.eecis.udel.edu/ นhnw/paper/acsac10.pdf

21. Tsou M, Zhang H, Jung CT. Identifying data noises, user biases, and system errors in geo-tagged Twitter messages (Tweets). ArXiv. Preprint posted online on December 6, 2017 [FREE Full text]

22. Ferrara E. What Types of COVID-19 Conspiracies are Populated by Twitter Bots? ArXiv. Preprint posted online on April 20, 2020 [FREE Full text]

23. Bernstein M, Monroy-Hernández A, Harry D, André P, Panovich K, Vargas G. 4chan and/b: An Analysis of Anonymity and Ephemerality in a Large Online Community. In: Proceedings of the Fifth International AAAI Conference on Weblogs and Social Media. 2011 Presented at: Fifth International AAAI Conference on Weblogs and Social Media; July 17-21, 2011; Barcelona, Spain URL: https://www.aaai.org/ocs/index.php/ICWSM/ICWSM11/paper/view/2873/4398

24. Weichselbraun A, Brasoveanu AMP, Waldvogel R, Odoni F. Harvest--An Open Source Toolkit for Extracting Posts and Post Metadata from Web Forums. ArXiv. Preprint posted online on February 3, 2021 [FREE Full text]

25. Signals Analytics. URL: https://www.signals-analytics.com [accessed 2020-12-11]

26. NetBase Quid. URL: https://netbasequid.com [accessed 2020-12-11]

27. Dong E, Du H, Gardner L. An interactive web-based dashboard to track COVID-19 in real time. Lancet Infect Dis 2020 May;20(5):533-534 [FREE Full text] [doi: 10.1016/S1473-3099(20)30120-1] [Medline: $\underline{\text { 32087114] }}$

28. Axisbits. COVID-19 Statistics API Documentation. Rapid API. URL: https://rapidapi.com/axisbits-axisbits-default/api/ covid-19-statistics/details [accessed 2021-06-15]

29. Han X, Wang J, Zhang M, Wang X. Using Social Media to Mine and Analyze Public Opinion Related to COVID-19 in China. Int J Environ Res Public Health 2020 Apr 17;17(8):1 [FREE Full text] [doi: 10.3390/ijerph17082788] [Medline: 32316647]

30. Jelodar H, Wang Y, Orji R, Huang S. Deep Sentiment Classification and Topic Discovery on Novel Coronavirus or COVID-19 Online Discussions: NLP Using LSTM Recurrent Neural Network Approach. IEEE J Biomed Health Inform 2020 Oct;24(10):2733-2742. [doi: 10.1109/JBHI.2020.3001216] [Medline: 32750931]

31. Nierenberg A, Pasick A. Schools Reopening: The State of Play for K-12. The New York Times. 2020 Aug 17. URL: https:/ /www.nytimes.com/2020/08/17/us/k-12-schools-reopening.html [accessed 2021-06-15]

32. Goodnough A, Sheikh K. CDC Weighs Advising Everyone to Wear a Mask. The New York Times. 2020 Mar 31. URL: https://www.nytimes.com/2020/03/31/health/cdc-masks-coronavirus.html [accessed 2021-06-15]

33. Sheikh K. You're Getting Used to Masks. Will You Wear a Face Shield? The New York Times. 2020 May 24. URL: https:/ /www.nytimes.com/2020/05/24/health/coronavirus-face-shields.html [accessed 2021-06-15]

34. Matzner P. Using Advanced Analytics for the Early Detection of Pandemics and Outbreaks. Signals Analytics. URL: https:/ /info.signals-analytics.com/research-paper-early-detection-pandemics [accessed 2021-06-15]

35. The Hill Media Bias | AllSides. AllSides. URL: https://www.allsides.com/news-source/hill-media-bias [accessed 2021-06-15]

36. Ribeiro F, Henrique L, Benevenuto F, Chakraborty A, Kulshrestha J, Babaei M. Media Bias Monitor: Quantifying Biases of Social Media News Outlets at Large-Scale. In: Proceedings of the Twelfth International AAAI Conference on Web and Social Media (ICWSM 2018). 2018 Presented at: Twelfth International AAAI Conference on Web and Social Media (ICWSM 2018); June 25-28, 2018; Palo Alto, CA URL: https://www.aaai.org/ocs/index.php/ICWSM/ICWSM18/paper/ view/17878/17020

37. Wan W, Dupree J. U.S. hits highest daily number of coronavirus cases since pandemic began. Washington Post. 2020 Oct 23. URL: https://www.washingtonpost.com/health/2020/10/23/covid-us-spike-cases/ [accessed 2021-06-15]

38. Katz J, Sanger-Katz M, Quealy K. A Detailed Map of Who Is Wearing Masks in the US. The New York Times. 2020 Jul 17. URL: https://www.nytimes.com/interactive/2020/07/17/upshot/coronavirus-face-mask-map.html [accessed 2021-06-15]

39. Brenan M. Americans' Face Mask Usage Varies Greatly by Demographics. Gallup. 2020 Jul 13. URL: https://news. gallup.com/poll/315590/americans-face-mask-usage-varies-greatly-demographics.aspx [accessed 2021-06-15]

40. Baker P, Haberman M. Trump Tests Positive for the Coronavirus. The New York Times. 2020 Oct 02. URL: https://www. nytimes.com/2020/10/02/us/politics/trump-covid.html [accessed 2021-06-15] 
41. Singer P, Flöck F, Meinhart C, Zeitfogel E, Strohmaier M. Evolution of reddit: from the front page of the internet to a self-referential community? ArXiv. Preprint posted online on February 6, 2014 [FREE Full text]

42. Molla R. How coronavirus took over social media. Vox. 2020 Mar 12. URL: https://www.vox.com/recode/2020/3/12/ 21175570/coronavirus-covid-19-social-media-twitter-facebook-google [accessed 2021-06-15]

43. Stokes D, Andy A, Guntuku SC, Ungar LH, Merchant RM. Public Priorities and Concerns Regarding COVID-19 in an Online Discussion Forum: Longitudinal Topic Modeling. J Gen Intern Med 2020 Jul;35(7):2244-2247 [FREE Full text] [doi: 10.1007/s11606-020-05889-w] [Medline: 32399912]

44. Cinelli M, Quattrociocchi W, Galeazzi A, Valensise CM, Brugnoli E, Schmidt AL, et al. The COVID-19 social media infodemic. Sci Rep 2020 Oct 06;10(1):16598 [FREE Full text] [doi: 10.1038/s41598-020-73510-5] [Medline: 33024152]

45. Chipidza W, Akbaripourdibazar E, Gwanzura T, Gatto NM. Topic Analysis of Traditional and Social Media News Coverage of the Early COVID-19 Pandemic and Implications for Public Health Communication. Disaster Med Public Health Prep 2021 Mar 03:1-8 [FREE Full text] [doi: 10.1017/dmp.2021.65] [Medline: 33653437]

46. Gozzi N, Tizzani M, Starnini M, Ciulla F, Paolotti D, Panisson A, et al. Collective Response to Media Coverage of the COVID-19 Pandemic on Reddit and Wikipedia: Mixed-Methods Analysis. J Med Internet Res 2020 Oct 12;22(10):e21597 [FREE Full text] [doi: 10.2196/21597] [Medline: 32960775]

47. Miller SG, Weaver J. Fauci Says U.S. Won't Get Back to Normal Until Late 2021. NBC News. 2020 Sep 11. URL: https:/ /www.nbcnews.com/health/health-news/fauci-says-us-won-t-get-back-normal-until-late-n1239882 [accessed 2021-06-15]

48. Ghader S, Zhao J, Lee M, Zhou W, Zhao G, Zhang L. Observed mobility behavior data reveal social distancing inertia. ArXiv. Preprint posted online on April 30, 2020 [FREE Full text]

49. Traffic Monitoring Count Data: Volume and Classification Information. CT.gov. URL: https://portal.ct.gov/DOT/PP SysInfo/ Traffic-Monitoring [accessed 2021-06-15]

50. Schuman R. INRIX U.S. National Traffic Volume Synopsis Issue \#15 (June 20 - June 26, 2020). INRIX. 2020 Jun 29. URL: https://inrix.com/blog/2020/06/covid19-us-traffic-volume-synopsis-15/ [accessed 2021-06-15]

51. Inferring gender of Reddit users. Vasilev E. 2018. URL: https://kola.opus.hbz-nrw.de/opus45-kola/frontdoor/deliver/index/ docId/1619/file/Master_thesis_Vasilev.pdf [accessed 2021-06-15]

52. Finlay SC. Age and Gender in Reddit Commenting and Success. Journal of Information Science Theory and Practice 2014 Sep 30;2(3):18-28. [doi: 10.1633/jistap.2014.2.3.2]

\section{Abbreviations}

API: application programming interface

NLP: natural language processing

Edited by C Basch; submitted 20.12.20; peer-reviewed by G Aguayo, M Nali; comments to author 01.02.21; revised version received
05.03.21; accepted 16.04.21; published 21.06.21
Please cite as:
Massey D, Huang C, Lu Y, Cohen A, Oren Y, Moed T, Matzner P, Mahajan S, Caraballo C, Kumar N, Xue Y, Ding Q, Dreyer R, Roy
B, Krumholz H
Engagement With COVID-19 Public Health Measures in the United States: A Cross-sectional Social Media Analysis from June to
November 2020
J Med Internet Res 2021;23(6):e26655
URL: $\underline{\text { https://www.jmir.org/2021/6/e26655 }}$
doi: $10.2196 / 26655$
PMID: $\underline{34086593}$

CDaisy Massey, Chenxi Huang, Yuan Lu, Alina Cohen, Yahel Oren, Tali Moed, Pini Matzner, Shiwani Mahajan, César Caraballo, Navin Kumar, Yuchen Xue, Qinglan Ding, Rachel Dreyer, Brita Roy, Harlan Krumholz. Originally published in the Journal of Medical Internet Research (https://www.jmir.org), 21.06.2021. This is an open-access article distributed under the terms of the Creative Commons Attribution License (https://creativecommons.org/licenses/by/4.0/), which permits unrestricted use, distribution, and reproduction in any medium, provided the original work, first published in the Journal of Medical Internet Research, is properly cited. The complete bibliographic information, a link to the original publication on https://www.jmir.org/, as well as this copyright and license information must be included. 